University of Nebraska - Lincoln

DigitalCommons@University of Nebraska - Lincoln

March 2006

\title{
Vibrational Feshbach resonances in uracil and thymine
}

\author{
Paul Burrow \\ University of Nebraska-Lincoln, pburrow1@unl.edu \\ Gordon A. Gallup \\ University of Nebraska-Lincoln, ggallup1@unl.edu \\ Adam M. Scheer \\ University of Nebraska-Lincoln, ascheer1@gmail.com \\ G. Denifl \\ Leopold-Franzens Universität Innsbruck \\ S. Ptasinska \\ Leopold-Franzens Universität Innsbruck \\ See next page for additional authors
}

Follow this and additional works at: https://digitalcommons.unl.edu/physicsburrow

Part of the Physics Commons

Burrow, Paul; Gallup, Gordon A.; Scheer, Adam M.; Denifl, G.; Ptasinska, S.; Märk, T.; and Scheier, P., "Vibrational Feshbach resonances in uracil and thymine" (2006). Paul Burrow Publications. 1.

https://digitalcommons.unl.edu/physicsburrow/1

This Article is brought to you for free and open access by the Research Papers in Physics and Astronomy at DigitalCommons@University of Nebraska - Lincoln. It has been accepted for inclusion in Paul Burrow Publications by an authorized administrator of DigitalCommons@University of Nebraska - Lincoln. 


\section{Authors}

Paul Burrow, Gordon A. Gallup, Adam M. Scheer, G. Denifl, S. Ptasinska, T. Märk, and P. Scheier 


\title{
Vibrational Feshbach resonances in uracil and thymine
}

\author{
P. D. Burrow, ${ }^{\text {a) }}$ G. A. Gallup, and A. M. Scheer \\ Department of Physics and Astronomy, University of Nebraska-Lincoln, Lincoln, Nebraska 68588-0111
}

S. Denifl, S. Ptasinska, T. Märk, and P. Scheier

Institute for Ion Physics and Center for Molecular Biosciences, Leopold-Franzens Universität Innsbruck, Technikerstrasse 25, A-6020 Innsbruck, Austria

(Received 16 November 2005; accepted 7 February 2006; published online 27 March 2006)

\begin{abstract}
Sharp peaks in the dissociative electron attachment (DEA) cross sections of uracil and thymine at energies below $3 \mathrm{eV}$ are assigned to vibrational Feshbach resonances (VFRs) arising from coupling between the dipole bound state and the temporary anion state associated with occupation of the lowest $\sigma^{*}$ orbital. Three distinct vibrational modes are identified, and their presence as VFRs is consistent with the amplitudes and bonding characteristics of the $\sigma^{*}$ orbital wave function. A deconvolution method is also employed to yield higher effective energy resolution in the DEA spectra. The site dependence of DEA cross sections is evaluated using methyl substituted uracil and thymine to block $\mathrm{H}$ atom loss selectively. Implications for the broader issue of DNA damage are briefly discussed. (C) 2006 American Institute of Physics. [DOI: 10.1063/1.2181570]
\end{abstract}

\section{INTRODUCTION}

Electron impact studies of the dissociative electron attachment (DEA) process in the RNA base uracil ${ }^{1}$ and the halouracils ${ }^{2}$ and of the total scattering cross sections of these compounds ${ }^{3}$ have revealed sharp structures at energies below $3 \mathrm{eV}$ that have been identified ${ }^{3}$ as vibrational Feshbach resonances (VFRs). ${ }^{4}$ With the aid of recent data taken by the Innsbruck group in methyl substituted uracil and thymine ${ }^{5}$ and the use of higher energy resolution, it is possible to assign these structures and elaborate on the DEA mechanisms in more detail.

In brief, uracil possesses a well studied dipole bound anionic state (DBS) lying 86-93 meV (Refs. 6 and 7) below the neutral molecule. The excited vibrational levels of the DBS lie in the scattering continuum and may in principle appear as VFRs. As outlined previously, ${ }^{3}$ mixing between the DBS and the temporary anion created by occupation of the lowest normally unoccupied valence $\sigma^{*}$ molecular orbital endows each anion state with some of the characteristics of the other. The vibrational modes that are "driven" by the transient occupation of the $\sigma^{*}$ orbital are therefore likely candidates for VFRs. If these levels lie above the energy threshold for the DEA process, they may appear as resonance peaks in the yield of negative ion fragments. In the case of uracil, two sharp structures in the production of $[\mathrm{U}-\mathrm{H}]^{-}+\mathrm{H}$ were identified $^{3}$ as the $\nu=2$ and 3 levels of the $\mathrm{N}_{1}-\mathrm{H}$ stretching mode. (Subscripts here refer to atom locations, as shown in Fig. 1.) The lifetimes of these resonances are consistent with $\mathrm{H}$ tunneling through the barrier created by the avoided crossing of the DBS and $\sigma^{*}$ anion potential surfaces. Calculations of the mixing between these states and the adiabatic anion potential energies as a function of the $\mathrm{N}_{1}-\mathrm{H}$ stretching coordinate have been presented elsewhere. ${ }^{8}$

\footnotetext{
a) Author to whom correspondence should be addressed. Electronic mail: pburrow1@unl.edu
}

In the present work, we discuss in more detail DEA measurements in uracil and thymine and their methylated congeners. Methylation at $\mathrm{N}_{1}$ or $\mathrm{N}_{3}$ selectively eliminates $\mathrm{H}$ loss at these sites, and the energy dependences of the DEA yields are found to be quite different, ${ }^{5}$ indicating the existence of two distinct dissociation mechanisms. In particular, they reveal whether DEA occurs through formation of VFRs or by coupling of the $\sigma^{*}$ and $\pi^{*}$ temporary anion states. Following this, we explore in detail the assignments of additional sharp structures in the DEA yield that are revealed by the use of higher electron beam resolution and deconvolution techniques. Our interpretations are guided by quantum chemical calculations of the relevant molecular orbitals and vibrational modes. An extended theoretical treatment of VFRs that includes multiple vibrational modes will be presented elsewhere. ${ }^{9}$

\section{EXPERIMENT}

The present investigations are performed in a crossed electron/molecule beam device described in detail previously. ${ }^{10}$ The electron beam is formed in a hemispherical electron monochromator, operated at an energy resolution between 60 and $110 \mathrm{meV}$ and an electron current of 5-8 nA. The molecular beam emanates from a source consisting of a temperature regulated oven and a capillary. For the compounds studied here, evaporation at $385-400 \mathrm{~K}$ results in an effusive beam of intact molecules. ${ }^{11}$ Negative ions formed in the collision zone are extracted by a weak electric field toward the entrance of the quadrupole mass spectrometer and detected by a single pulse counting technique. The intensity of the mass-selected negative ion is recorded as a function of the electron energy. The electron energy scale is calibrated using the well known $\mathrm{Cl}^{-} / \mathrm{CCl}_{4}$ anion yield near $0 \mathrm{eV} .{ }^{12}$ The compounds were purchased from Sigma-Aldrich at a stated purity of $98 \%$. 


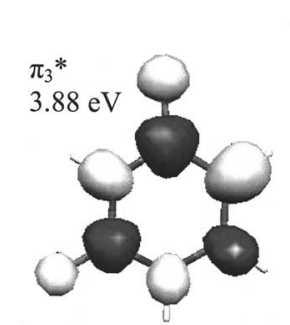

Uracil
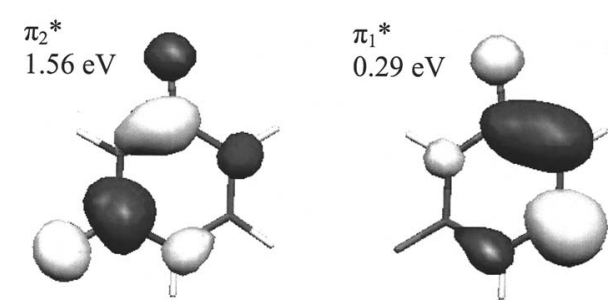

FIG. 1. Sketches of the three lowest $\pi^{*}$ molecular orbitals of uracil. The measured energies of the temporary anion states associated with each of the orbitals are given.

\section{ANION STATES}

\section{A. Valence anion states}

The wave functions and energies of the relevant temporary anion states play a fundamental role in the following discussions. The simplest means to obtain estimates of these is by the use of calculated virtual orbitals (VOs) and energies (VOEs) of the neutral molecules. For this purpose we have used the GAMESS suite of programs ${ }^{13}$ with $6-31 \mathrm{G}(d)$ basis sets for both geometry optimization and electronic structure. In Fig. 1 we show the three lowest empty orbitals of $\pi$ symmetry in uracil, labeled $\pi_{1}^{*}-\pi_{3}^{*}$, where the asterisk indicates "antibonding." The experimental energies for electron attachment into these orbitals, the vertical attachment energies (VAEs), as determined by electron transmission spectroscopy, are also given. ${ }^{3,14}$ Thymine is identical to uracil except for a methyl group at $\mathrm{C}_{5}$, and not surprisingly the corresponding $\pi^{*}$ orbitals are very similar in appearance and are not shown.

Figure 2 shows the two lowest empty valence orbitals of $\sigma$ symmetry in uracil and three lowest in thymine. Unlike the $\pi^{*}$ orbitals, the temporary anion states created by occupation of the $\sigma^{*}$ orbitals have not been observed in the total scattering cross sections. Several factors are likely to contribute to this. The $\sigma^{*}$ resonances have shorter lifetimes and are repulsive along some nuclear coordinates, both of which tend to produce broad peaks. Furthermore, the presence of the three pronounced $\pi^{*}$ resonances also tends to obscure them. In the absence of experimental evidence for their energies, we are
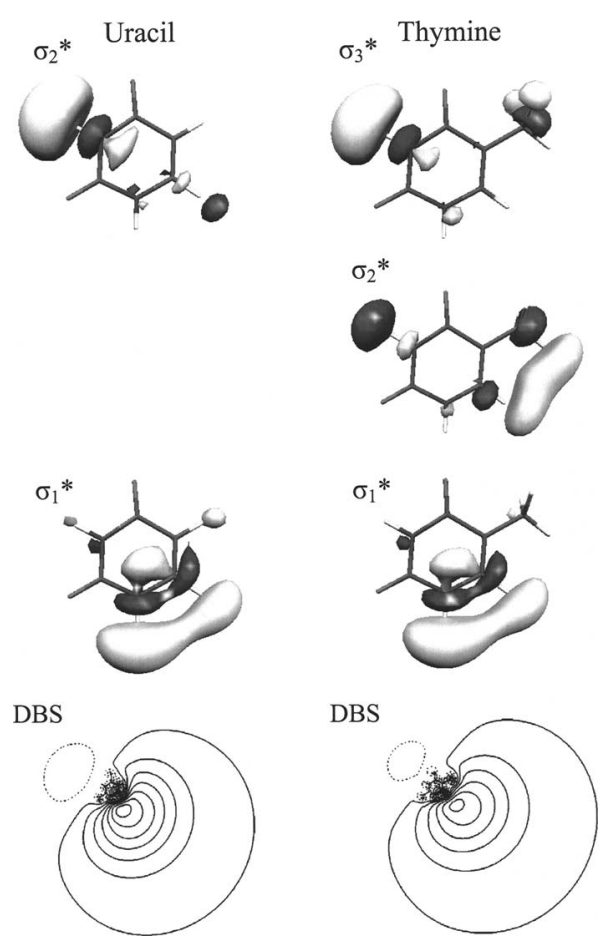

FIG. 2. Sketches of the lowest valence $\sigma^{*}$ orbitals of uracil (left) and thymine (right) and contour representations of the dipole bound anion states of these molecules (bottom).

forced to rely on calculated estimates. Computed VOEs are known to be too large for reasons that are well understood. ${ }^{15}$ However, good approximations to $\pi^{*}$ resonance energies have been obtained by shifting and scaling $\pi^{*}$ VOEs to match measured energies in related families of molecules. ${ }^{15,16}$ Such work in the DNA bases has been reported elsewhere. $^{14}$

For $\sigma^{*}$ resonances, the most extensively observed temporary anion states are those associated with $\mathrm{C}-\mathrm{Cl} \sigma^{*}$ orbitals in chlorine substituted molecules, ${ }^{17}$ and we use the scaling $\{\mathrm{VAE}=0.90 \mathrm{VOE}-2.55\}$ derived from this work to estimate the anion energies. These values are listed as the "scaled VOEs" in Table I. We note that the $\sigma_{1}^{*}$ resonance in thymine is predicted to lie slightly higher than that of uracil. The $\sigma_{1}^{*}$ wave functions appear almost identical. The $\sigma_{2}^{*}$ orbital of uracil and $\sigma_{3}^{*}$ orbital of thymine are also quite similar, primarily antibonding between $\mathrm{N}_{3}-\mathrm{H}$, and their energies are relatively close. Thymine displays an additional low lying orbital, $\sigma_{2}^{*}$, not present in uracil, which is antibonding between $\mathrm{C}_{6}-\mathrm{H}$ and between the methyl $\mathrm{CH}_{2}-\mathrm{H}$, as well as $\mathrm{N}_{3}-\mathrm{H}$.

TABLE I. Virtual orbital energies (VOEs) and scaled VOEs (SVOEs) (scaled VOE=0.90VOE-2.55, energies in $\mathrm{eV}$ ) from $6-31 \mathrm{G}(d)$ basis set calculations, in $\mathrm{eV}$.

\begin{tabular}{ccccccc}
\hline \hline Cmpd. & $\sigma_{1}^{*}$ VOE & $\sigma_{1}^{*}$ SVOE & $\sigma_{2}^{*}$ VOE & $\sigma_{2}^{*}$ SVOE & $\sigma_{3}^{*}$ VOE & $\sigma_{3}^{*}$ SVOE \\
\hline Uracil & 5.34 & 2.26 & 6.91 & 3.67 & 7.13 & 3.87 \\
Thymine & 5.50 & 2.40 & 6.63 & 3.42 & 7.00 & 3.75 \\
3-MeU & 5.50 & 2.40 & 7.19 & 3.92 & 7.45 & 4.15 \\
1-MeT & 6.17 & 3.00 & 6.74 & 3.52 & 6.85 & 3.62 \\
\hline \hline
\end{tabular}




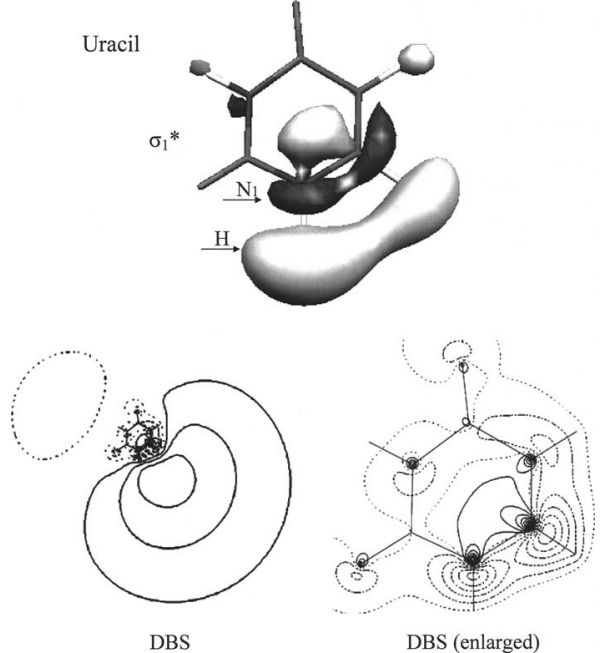

FIG. 3. The $\sigma_{1}^{*}$ orbital and an expanded view of the dipole bound anion state of uracil on the molecular frame.

\section{B. Dipole bound states}

At the bottom of Fig. 2, our calculated wave functions for the dipole bound anion states of uracil and thymine are shown. These states were optimized at the 6-311G $(d)$ level augmented with four Gaussian sets of $\left\{s, p_{x}, p_{y}, p_{z}\right\}$ orbitals with scale factors of $0.04,0.004,0.0004$, and 0.00004 . For uracil these were centered on the $\mathrm{N}_{1} \mathrm{H}$ atom and for $\mathrm{T}$ on the $\mathrm{C}_{6} \mathrm{H}$ atom. Such states have been the subject of numerous higher level calculations. ${ }^{18,19}$ Our purpose here is to show the orientation of this wave function with respect to those of the $\sigma^{*}$ orbitals lying above it. We note that the dipole moment of thymine is rotated $6.5^{\circ}$ counterclockwise, relative to the molecular frame, with respect to that of uracil. In Fig. 3 we show an expanded view of the dipole bound state showing the portion of the wave function residing on the molecular frame, for comparison with $\sigma_{1}^{*}$.

\section{SITE DEPENDENCE OF DEA IN URACIL AND THYMINE}

The close similarity of the DEA spectra of uracil and thymine below $3 \mathrm{eV}$ as observed in the production of $[\mathrm{U}-\mathrm{H}]^{-}$and $[\mathrm{T}-\mathrm{H}]^{-}$, respectively, is apparent from previous work. ${ }^{20}$ A number of subtle differences exist, and these will be explored later in this work. As Abdoul-Carime et al. ${ }^{21}$ observed earlier, the DEA spectrum of thymine deuterated everywhere except at the $\mathrm{N}_{1}$ and $\mathrm{N}_{3}$ positions is virtually identical to that of the undeuterated compound. This implies that the loss of $\mathrm{H}$ only occurs from the nitrogen sites.

Using DEA data from 3-methyluracil (3-MeU) and 1-methylthymine (1-MeT), loss of $\mathrm{H}$ from the $\mathrm{N}_{3}$ and $\mathrm{N}_{1}$ sites may be explored selectively. (Methyl substitution alters the resonance energies slightly from those in uracil and thymine. See Table I.) As shown in Fig. 4, the spectrum of 3-MeU (allowing loss of $\mathrm{H}$ only from the $\mathrm{N}_{1}$ site) contains sharp features observed previously in unsubstituted uracil. The spectrum of 1-MeT (allowing loss of $\mathrm{H}$ only from the $\mathrm{N}_{3}$ site), on the other hand, displays a smooth but skewed bell-

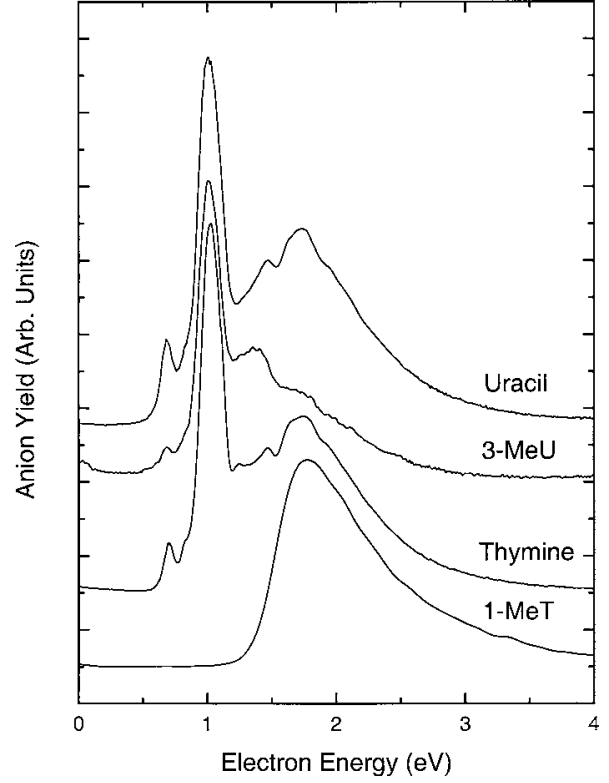

FIG. 4. Negative ion yield as a function of electron energy in uracil, 3-methyluracil, thymine, and 1-methylthymine.

shaped curve, suggesting an entirely different mechanism. A weighted summation of these two spectra, in fact, emulates the uracil spectrum rather well (not shown).

As summarized briefly in the Introduction, the two pronounced features in the production of $[\mathrm{U}-\mathrm{H}]^{-}+\mathrm{H}$ at 0.69 and $1.01 \mathrm{eV}$ were identified ${ }^{3}$ as the $\nu=2$ and 3 levels of the $\mathrm{N}_{1}-\mathrm{H}$ stretching mode associated with the dipole bound anion state. The wave functions for the low lying empty $\sigma^{*}$ valence orbitals of these compounds and that for the DBS shown in Figs. 2 and 3 will clarify this mechanism. Because the positive pole of the electric dipole lies on the side of the molecule containing $\mathrm{C}_{6}$ and $\mathrm{N}_{1}$, there is excellent spatial overlap between the wave function of the DBS and that of the lowest valence $\sigma_{1}^{*}$ orbital of both $\mathrm{U}$ and T. Mixing between these two anion states is calculated ${ }^{8,9}$ to be quite substantial, and, as shown in Fig. 5, leads to an avoided crossing of the $\sigma_{1}^{*}$ anion and DBS potential curves when plotted as a function of the $\mathrm{N}_{1}-\mathrm{H}$ separation. At the position where the crossing between the two diabatic curves would occur, the

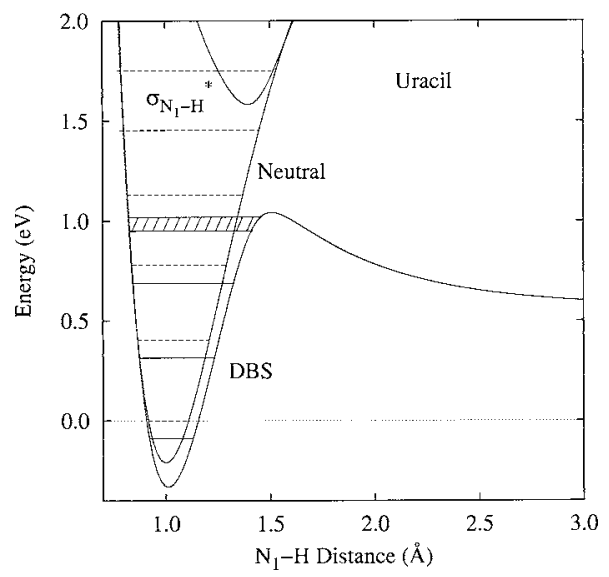

FIG. 5. Potential energies of the neutral, dipole bound state, and valence $\sigma^{*}$ anion state as a function of $\mathrm{N}_{1}-\mathrm{H}$ separation, as described in Ref. 8 . 
energy difference between the adiabatic curves is computed to be $0.602 \mathrm{eV}^{8}$. The sharp structure in the DEA spectrum thus arises from VFRs whose lifetimes are determined by $\mathrm{H}$ tunneling rates through the barrier created by the avoided crossing. The amplitudes of these peaks are determined by Franck-Condon factors between the nuclear wave function of the ground vibrational level of the neutral molecule and those of the VFRs.

The $\mathrm{H}$ tunneling mechanism is supported by the work elsewhere in which uracil has been deuterated at both the $\mathrm{N}_{1}$ and $\mathrm{N}_{3}$ positions. ${ }^{8}$ The DEA spectrum is substantially altered, with no visible sharp contributions from VFRs. This was attributed to the lower tunneling rate of the $\mathrm{D}$ atom relative to $\mathrm{H}$ as well as shifts in the VFR energies. Consistently, in 1-MeT, where the $\mathrm{H}$ on $\mathrm{N}_{1}$ has been replaced by the even more massive methyl group, VFRs associated with the $\mathrm{N}_{1}$ site are even more suppressed, and only the $\mathrm{H}$ on $\mathrm{N}_{3}$ can participate in DEA.

In contrast to the large mixing between $\sigma_{1}^{*}$ and the DBS wave function, the geometry is much less favorable for mixing between $\sigma_{2}^{*}$ and the DBS in uracil. As seen in Fig. 2, the $\sigma_{2}^{*}$ orbital is localized primarily on the $\mathrm{N}_{3}-\mathrm{H}$ bond, that is, on the side close to the negative end of the electric dipole and thus there is little spatial overlap between the wave functions. Furthermore, the energy of this orbital, see Table I, lies higher in energy than that of $\sigma_{1}^{*}$, further reducing the mixing. Similarly, the $\sigma_{2}^{*}$ and $\sigma_{3}^{*}$ orbitals in thymine contain sizeable wave function amplitudes at $\mathrm{N}_{3}-\mathrm{H}$, remote from the DBS wave function. Although there is amplitude in $\sigma_{2}^{*}$ on $\mathrm{C}_{6}-\mathrm{H}$ and $\mathrm{C}-\mathrm{H}$ of the methyl group that might overlap the DBS wave function, the calculated thresholds for loss of $\mathrm{H}$ from these latter two sites are considerably higher in energy, ${ }^{1(\mathrm{a}), 22}$ and they are not expected to play a role at these electron energies. Consequently, the DEA yield in 1-MeT must arise through a mechanism that does not involve coupling of the $\sigma^{*}$ orbitals to that of the DBS.

In numerous DEA studies of planar unsaturated hydrocarbons substituted with halogens, ${ }^{23}$ it is found that the maxima in DEA yields occur at the energies of the $\pi^{*}$ resonances. The mechanism is believed to take place by nonplanar distortions resulting from occupation of a $\pi^{*}$ orbital which then permit coupling to a repulsive $\sigma^{*}$ anion state or, alternately, by vibronic coupling between these two temporary anion states. In the present compounds, the $\pi_{1}^{*}$ anion states lie below the asymptotic energy for production of the $[\mathrm{U}-\mathrm{H}]^{-}$or $[\mathrm{T}-\mathrm{H}]^{-}$anion fragment and cannot be involved. Furthermore, the $\sigma_{1}^{*}$ anion states have very little wave function amplitude at the $\mathrm{N}_{3}-\mathrm{H}$ site. Thus the coupling is likely to occur between the $\sigma_{2}^{*}$ and $\pi_{2}^{*}$ orbitals. There are two observations in support of this interpretation. First, we note that the VAE of the $\pi_{2}^{*}$ resonance has been determined to be $1.71 \mathrm{eV}$ (Ref. 14) in thymine, in good agreement with the DEA peak energy, $1.74 \mathrm{eV}$, seen in Fig. 4. Second, as shown by calculations elsewhere, ${ }^{1(a)}$ the threshold energy for loss of the $\mathrm{H}$ atom on $\mathrm{N}_{3}$ is computed to be $1.4 \mathrm{eV}$. The rapid rise in the DEA cross section near this energy therefore reflects a near vertical onset for this process and further confirms that $\mathrm{H}$ loss arises from the $\mathrm{N}_{3}$ site.

While we offer no calculations to support the $\pi_{2}^{*} / \sigma_{2}^{*}$ mixing, it may be worth noting that the maximum wave function coefficients of the $\pi_{2}^{*}$ orbital of uracil (Fig. 1) are located near $\mathrm{C}_{2}, \mathrm{~N}_{3}$, and $\mathrm{C}_{4}$. Distortions out of plane will be preferentially driven in this region of the molecule and will couple most strongly to $\sigma_{2}^{*}$ on $\mathrm{N}_{3}-\mathrm{H}$. Such a mechanism might also help to explain why there is no evidence for production of $[\mathrm{U}-\mathrm{H}]^{-}$via coupling between $\pi_{2}^{*}$ and $\sigma_{1}^{*}$. In this case, the $\sigma_{1}^{*}$ coefficients are maximum on the side of the molecule opposite those of the $\sigma_{2}^{*}$ orbital.

\section{VFRs IN URACIL AND THYMINE}

We turn next to examine the VFRs in more detail, in particular, with respect to additional sharp features in the DEA spectra that are revealed with higher energy resolution. Starting with data taken with an improved resolution of $60 \mathrm{meV}$, an approximate deconvolution method was applied. The electron energy distribution was determined from the anion efficiency curve of $\mathrm{Cl}^{-}$formed via DEA to $\mathrm{CCl}_{4}$. The cross section for this process follows an $E^{-1}$ (and $E^{-0.5}$ at very low energies) energy dependence and can be approximated as a delta function. The measured ion yield of $\mathrm{Cl}^{-}$is a convolution of the cross section with the electron energy distribution and thus can be considered as the instrumental electron energy distribution. In the present study, the shape of the $\mathrm{Cl}^{-}$anion yield is almost a narrow Gaussian peak. The deconvolution of two such Gaussian peaks with corresponding widths $w_{1}$ and $w_{2}$ results in another Gaussian that has a width of

$$
w_{\mathrm{dec}}=\sqrt{w_{1}^{2}-w_{2}^{2}} .
$$

The DEA yields of the compounds were fitted with multiple Gaussians (up to 12) and the deconvolution was achieved by reducing the width of each individual Gaussian according to Eq. (1). Finally, the quality of this deconvolution procedure was checked by a comparison of the measured data with convolution of the resulting cross section with the electron energy distribution. Although computationally convenient, this scheme has two deficiencies that should be noted. First, the resonance peaks are actually Lorentzian in profile rather than Gaussian. Secondly, the $\mathrm{Cl}^{-} / \mathrm{CCl}_{4}$ cross section near zero energy is not a symmetric function and thus is not ideal for this application.

Figures 6-8 present the measured DEA yields (lower curves) in 3-MeU, thymine, and uracil, respectively. The upper curves (red) illustrate the effective enhancement in energy resolution of the deconvoluted DEA yields as a function of electron energy. Vertical dotted lines guide the eye from the peaks to the assigned VFRs.

As we have discussed, the 0.7 and $1.01 \mathrm{eV}$ DEA peaks in uracil and thymine are VFRs associated with $\mathrm{N}_{1}-\mathrm{H}$ vibrations, oscillations that are driven by the strongly antibonding character of the $\sigma_{1}^{*}$ valence orbital between $\mathrm{N}_{1}$ and $\mathrm{H}$ (Figs. 2 and 3). Now we call attention to the fact that this orbital is also strongly antibonding between $\mathrm{C}_{6}$ and $\mathrm{H}$ and bonding between $\mathrm{N}_{1}$ and $\mathrm{C}_{6}$, as well as between the $\mathrm{H}$ atoms attached to them. Thus upon temporary occupation of this orbital, we expect excitation of the $\mathrm{C}_{6}-\mathrm{H}$ stretching vibration at $381 \mathrm{meV}$, the $\mathrm{N}_{1}-\mathrm{C}_{6}$ stretch at $134 \mathrm{meV}$, and the in-plane 


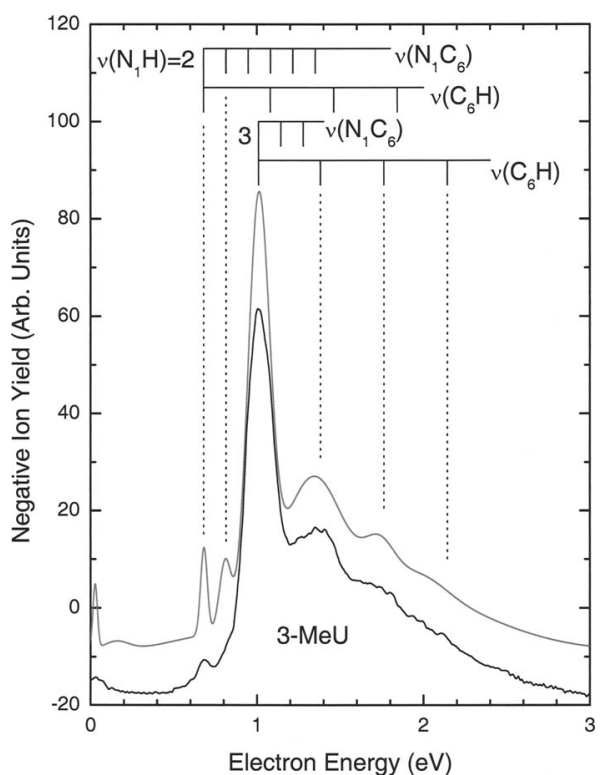

FIG. 6. Negative ion yield as a function of electron energy in 3-methyluracil, lower curve at $\sim 60 \mathrm{meV}$ resolution. Upper curve in red: deconvoluted yield. Energy levels of the vibrational modes associated with the $\mathrm{N}_{1}-\mathrm{H}$ stretch, the $\mathrm{C}_{6}-\mathrm{H}$ stretch and the $\mathrm{N}_{1}-\mathrm{C}_{6}$ stretch are indicated with short vertical lines.

$\mathrm{H}$ wagging vibration, lying at $147 \mathrm{meV}$ in the neutral, ${ }^{24}$ along with the $\mathrm{N}_{1}-\mathrm{H}$ stretch. Supporting evidence for this, in part, is seen in the vibrational energy losses measured by Abouaf et $a l .{ }^{25}$ in thymine. Unfortunately for our purposes, their impact energy was chosen to coincide with that of the $\pi_{2}^{*}$ resonance at $1.7 \mathrm{eV}$. Nevertheless, there is also some excitation through the broad $\sigma_{1}^{*}$ resonance taking place at this energy, and losses corresponding to the $\mathrm{N}_{1}-\mathrm{H}$ vibration are prominent, along with smaller amounts of the $\mathrm{C}_{6}-\mathrm{H}$ stretch. The $\mathrm{H}$ wag and $\mathrm{C}_{6}-\mathrm{N}_{1}$ stretch are not identified specifically, but may be buried under numerous modes excited through the $\pi_{2}^{*}$ resonance.

Thus, with respect to coupling between the DBS and the

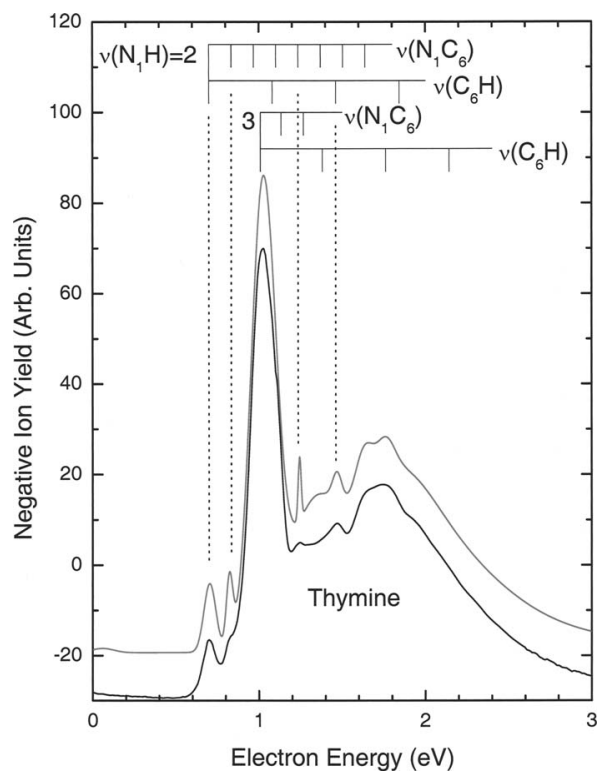

FIG. 7. As in Fig. 6 for thymine.

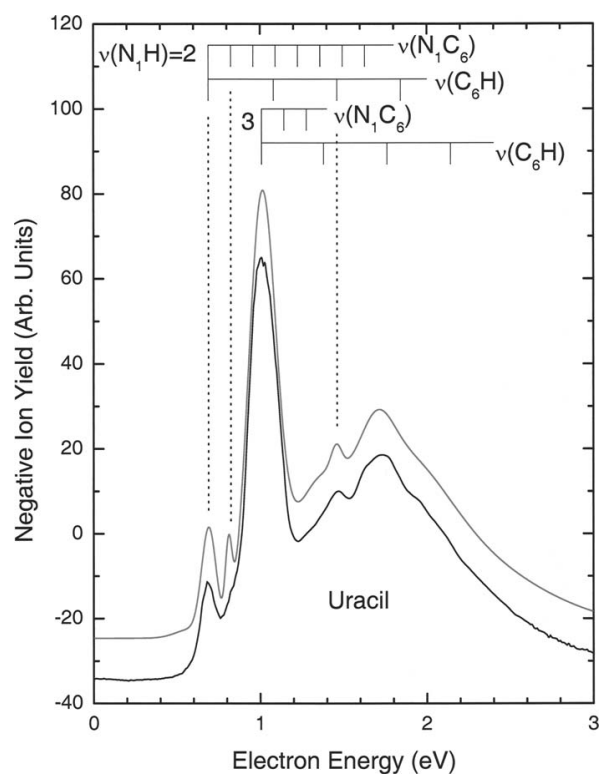

FIG. 8. As in Fig. 6 for uracil.

resonance associated with occupation of the $\sigma_{1}^{*}$ orbital, there are four vibrational modes that are candidates to appear as VFRs in the DEA yield. For convenience we label these as $\nu\left(\mathrm{N}_{1} \mathrm{H}\right), \nu\left(\mathrm{C}_{6} \mathrm{H}\right), \nu\left(\mathrm{N}_{1} \mathrm{C}_{6}\right)$, and $\nu(\beta)$, the latter being the $\mathrm{H}$ wag. It is important to note that only the $\nu\left(\mathrm{N}_{1} \mathrm{H}\right)$ mode results in $\mathrm{H}$ motion toward a barrier (Fig. 5) that can be penetrated at these energies. Consequently, the presence of vibrational energy in the other modes is not expected to affect substantially the tunneling lifetimes of the $\nu\left(\mathrm{N}_{1} \mathrm{H}\right)=2$ and 3 VFRs. Thus, the vibrations building on $\nu\left(\mathrm{N}_{1} \mathrm{H}\right)=2$ will have narrow widths characteristic of the $0.7 \mathrm{eV}$ peak while those building on $\nu\left(\mathrm{N}_{1} \mathrm{H}\right)=3$ will be broad like the $1.01 \mathrm{eV}$ peak.

At the top of Figs. 6-8, we indicate the vibrational levels that produce the best overall agreement with the measured results. Because the $\nu\left(\mathrm{N}_{1} \mathrm{H}\right)$ energies in the anion state are strongly anharmonic, the $\nu\left(\mathrm{N}_{1} \mathrm{H}\right)=2$ and 3 levels cannot be easily predicted from the corresponding levels in the neutral molecule, and thus these are positioned in the figures to agree with the experimental peaks. Building on each of these levels are the $\nu\left(\mathrm{C}_{6} \mathrm{H}\right)$ vibrations spaced at $381 \mathrm{meV}$ and the $\nu\left(\mathrm{N}_{1} \mathrm{C}_{6}\right)$ mode at $134 \mathrm{meV}$ as given in the neutral molecule. Calculations ${ }^{9}$ indicate that the energies of the relevant vibrational modes in the dipole bound anion differ very little from those in the neutral. No evidence for peaks associated with the in-plane $\mathrm{H}$ wagging vibration at $147 \mathrm{meV}$ in the neutral was seen in the data. Now we turn to a discussion of the individual compounds.

\section{A. 3-methyluracil}

As discussed earlier, all of the DEA peaks in this compound arise entirely from $\mathrm{H}$ atom loss at the $\mathrm{N}_{1}$ site. Building on $\nu\left(\mathrm{N}_{1} \mathrm{H}\right)=2$, an additional narrow feature is seen that is consistent with one additional vibrational quantum of $\nu\left(\mathrm{N}_{1} \mathrm{C}_{6}\right)$. In the untreated data, this peak appears only as a shoulder. The next few levels of this mode are likely to be obscured by $\nu\left(\mathrm{N}_{1} \mathrm{H}\right)=3$. 
On the high energy side of the $\nu\left(\mathrm{N}_{1} \mathrm{H}\right)=3$ peak, three broad peaks appear whose energies are consistent with $\nu\left(\mathrm{C}_{6} \mathrm{H}\right)=1,2$, and 3 . Note that the widths of these features are comparable to that of $\nu\left(\mathrm{N}_{1} \mathrm{H}\right)=3$. Similar broad peaks from $\nu\left(\mathrm{N}_{1} \mathrm{C}_{6}\right)$, building on $\nu\left(\mathrm{N}_{1} \mathrm{H}\right)=3$ would likely be obscured by their smaller spacing.

\section{B. Thymine}

The most numerous VFR structures appear in thymine, shown in Fig. 7. In addition to the two peaks associated with $\nu\left(\mathrm{N}_{1} \mathrm{H}\right)=2$, namely, $\nu\left(\mathrm{N}_{1} \mathrm{C}_{6}\right)=0$ and 1 , two other members of the sharp series appear that we assign to $\nu\left(\mathrm{N}_{1} \mathrm{C}_{6}\right)=4$ and $\nu\left(\mathrm{C}_{6} \mathrm{H}\right)=2$, again indicated by the vertical dotted lines. Other structures at higher energy may consist of additional combinations of these modes but the assignments are less certain and we omit them. All of these structures lie on top of the broad undulations associated with $\nu\left(\mathrm{N}_{1} \mathrm{H}\right)=3, \nu\left(\mathrm{C}_{6} \mathrm{H}\right)=1,2$, and 3 discussed earlier in $3-\mathrm{MeU}$.

\section{Uracil}

The DEA spectrum of uracil in Fig. 8 is quite similar to that of thymine, although the sharp peak assigned to $\nu\left(\mathrm{N}_{1} \mathrm{H}\right)=2, \nu\left(\mathrm{N}_{1} \mathrm{C}_{6}\right)=4$ in the latter is barely visible in the untreated data, if at all. The collected data suggest that the lifetimes of all the VFRs in uracil are somewhat shorter than those of thymine. As we noted earlier, the $\sigma_{1}^{*}$ orbital energies in these two compounds differ slightly, with that of thymine being slightly higher. The VFR lifetimes are very sensitive to the energy of the barrier created by the avoided crossing between the DBS and the temporary anion state associated with the $\sigma_{1}^{*}$ orbital. $^{8}$ A slightly higher barrier in thymine could thus account for the differences in the spectra.

During preparation of this work for publication, a paper by Abouaf and Dunet ${ }^{26}$ was published showing DEA structures in thymine, uracil, and halouracils with electron resolutions from 25 to $60 \mathrm{meV}$. The shapes of the spectra agree very well with those presented here, falling between the untreated and the deconvoluted data with regard to energy resolution. Consequently, the features in uracil and thymine, unassigned by Abouaf and Dunet, are completely accounted for by the present interpretation.

Another issue raised by these authors has already been resolved. Given the first estimates of the DEA cross section associated with the $\nu\left(\mathrm{N}_{1} \mathrm{H}\right)=3$ peak in uracil, ${ }^{1(\mathrm{a})}$ it was puzzling that this feature did not appear in the total scattering cross section as observed by electron transmission spectroscopy (ETS). ${ }^{3}$ However, as shown by Aflatooni et al. ${ }^{27}$ the DEA cross section is substantially smaller than initially reported, and its absence is not surprising.

The peak energies reported by Abouaf and Dunet ${ }^{26}$ differ slightly from those of the Innsbruck group. In both cases, calibration is carried out by reference to a DEA cross section that diverges at zero energy. Two cautions are necessary here. As shown by Klar et al., ${ }^{28}$ such a cross section convoluted with an instrumental electron energy distribution yields a peak whose maximum is shifted above zero by an amount that is a function of the full width at half maximum of the distribution. Thus, taking this peak as the "zero" energy ref- erence will cause sharp structure located well above zero to appear at a lower energy than it should. Furthermore, because of stray electric fields, the electron beam may well be retarded before reaching zero energy. This will also cause peak energies to appear lower than they should.

\section{CONCLUSIONS}

This combined work has demonstrated the following.

(a) The production of $[\mathrm{U}-\mathrm{H}]^{-}$and $[\mathrm{T}-\mathrm{H}]^{-}$from uracil and thymine that proceeds through loss of $\mathrm{H}$ from the $\mathrm{N}_{3}$ site takes place by $\pi_{2}^{*} / \sigma_{2}^{*}$ mixing and produces a broad peak at the energy of the $\pi_{2}^{*}$ resonance with no evidence for sharp structure. The rapid increase of the low energy side of the peak suggests a vertical onset.

(b) Anion production by loss of $\mathrm{H}$ from the $\mathrm{N}_{1}$ site is dominated by the presence of VFRs created by mixing of the dipole bound anion state with the lowest valence $\sigma_{1}^{*}$ resonance. VFRs associated with three different vibrational modes are present. These are modes that would be given a strong impulse by temporary electron occupation of this orbital.

(c) Only the $\mathrm{N}_{1} \mathrm{H}$ atom is driven toward a barrier through which it can tunnel. Therefore, the widths of VFRs building on $\nu\left(\mathrm{N}_{1} \mathrm{H}\right)=2$ have characteristically narrow widths and those building on $\nu\left(\mathrm{N}_{1} \mathrm{H}\right)=3$ are broad.

A few final comments may be in order regarding the role of the mechanisms discussed here and the broader issue of damage to DNA through temporary anion formation. As shown by the DEA yield in 1-MeT, methylation at the $\mathrm{N}_{1}$ site (and even deuteration in uracil at $\mathrm{N}_{1}$ ) eliminates the yield arising from VFRs. This follows simply from the much reduced tunneling rates of these heavy species. Consequently, gas phase studies of thymine attached to a ribose ring at $\mathrm{N}_{1}$ (thymidine) that show production of $[\mathrm{T}-\mathrm{H}]^{-}$with the same sharp structures as found in electron impact on thymine itself, ${ }^{29}$ must be in error. This signal likely arises from a thymine impurity originating through decomposition of the parent compound in the oven.

Ptasinska et $a l .{ }^{5}$ have suggested recently that the absence of DEA yield associated with bond breaking at the $\mathrm{N}_{1}$ site in 1-MeT has significant consequences for the description of strand breaks induced by low energy electrons in DNA. Because the $\mathrm{N}_{1}$ position is coupled to the sugar moiety in DNA, they argue that that "transfer of charge and energy via the $\mathrm{N}_{1}-\mathrm{C}$ bond will not take place." This conclusion is premature. It should be remembered that decay of a temporary anion state into a DEA channel is generally only a small part of the total cross section for resonance formation. Its absence therefore does not rule out other mechanisms for transport of an electron, such as mixing of the $\pi^{*}$ wave functions on the bases with empty $\sigma^{*}$ orbitals on the ribose and phosphate entities, that is, "though bond" interactions. As modeled by Barrios et al. ${ }^{30}$ such mixing could ultimately transfer an electron and break a remote bond. Such processes have been observed previously in rigid chloroalkenes, ${ }^{31}$ acting through as many as four saturated bonds. 


\section{ACKNOWLEDGMENTS}

Work by the Innsbruck group was supported in part by the FWF, Wien, Austria, and the EU via the EU Network EPIC.

${ }^{1}$ (a) G. Hanel, B. Gstir, S. Denifl, P. Scheier, M. Probst, B. Farizon, M. Farizon, E. Illenberger, and T. D. Märk, Phys. Rev. Lett. 90, 188104 (2003); (b) S. Denifl, S. Ptasinska, G. Hanel, B. Gstir, M. Probst, P. Scheier, and T. D. Märk, J. Chem. Phys. 120, 6557 (2004).

${ }^{2}$ S. Denifl, S. Matejcik, B. Gstir, G. Hanel, M. Probst, P. Scheier, and T. D. Märk, J. Chem. Phys. 118, 4107 (2003); R. Abouaf, J. Pommier, and H. Dunet, Int. J. Mass. Spectrom. 226, 397 (2003); H. Abdoul-Carime, M. A. Huels, E. Illenberger, and L. Sanche, ibid. 228, 703 (2003).

${ }^{3}$ A. M. Scheer, K. Aflatooni, G. A. Gallup, and P. D. Burrow, Phys. Rev. Lett. 92, 068102 (2004).

${ }^{4}$ H. Hotop, M.-W. Ruf, M. Allan, and I. I. Fabrikant, Adv. At., Mol., Opt. Phys. 49, 85 (2003)

${ }^{5}$ S. Ptasinska, S. Denifl, P. Scheier, E. Illenberger, and T. D. Märk, Angew. Chem., Int. Ed. 44, 6941 (2005).

${ }^{6}$ J. H. Hendricks, S. A. Lyapustina, H. L. de Clercq, J. T. Snodgrass, and K. H. Bowen, J. Chem. Phys. 104, 7788 (1996).

${ }^{7}$ J. Scheidt, R. Weinkauf, D. M. Neumark, and E. W. Schlag, Chem. Phys. 239, 511 (1998)

${ }^{8}$ A. M. Scheer, C. Silvernail, J. A. Belot, K. Aflatooni, G. A. Gallup, and P. D. Burrow, Chem. Phys. Lett. 411, 46 (2005).

${ }^{9}$ G. A. Gallup (unpublished).

${ }^{10}$ D. Muigg, G. Denifl, A. Stamatovic, O. Echt, and T. D. Märk, Chem. Phys. 239, 409 (1998).

${ }^{11}$ S. Ptasinska, S. Denifl, V. Grill, T. D. Märk, P. Scheier, S. Gohlke, M. A. Huels, and E. Illenberger, Angew. Chem., Int. Ed. 44, 1647 (2005).

${ }^{12}$ S. Matejcik, G. Senn, P. Scheier, A. Kiendler, A. Stamatovic, and T. D. Märk, J. Chem. Phys. 107, 8955 (1997).

${ }^{13}$ M. W. Schmidt, K. K. Baldridge, J. A. Boatz et al., J. Comput. Chem.
14, 1347 (1993).

${ }^{14}$ K. Aflatooni, G. A. Gallup, and P. D. Burrow, J. Phys. Chem. A 102, 6205 (1998).

${ }^{15}$ See, for example, D. Chen and G. A. Gallup, J. Chem. Phys. 93, 8893 (1990).

${ }^{16}$ S. W. Staley and J. T. Strnad, J. Phys. Chem. 98, 116 (1994).

${ }^{17}$ See, for example, K. Aflatooni, G. A. Gallup, and P. D. Burrow, J. Phys. Chem. A 104, 7359 (2000).

${ }^{18}$ D. M. A. Smith, J. Smets, Y. Elkadi, and L. Adamowicz, J. Phys. Chem. A 101, 8123 (1997).

${ }^{19}$ O. Dolgounitcheva, V. G. Zakrzewski, and J. V. Ortiz, Chem. Phys. Lett. 307, 220 (1999).

${ }^{20}$ S. Denifl, S. Ptasinska, M. Cingel, S. Matejcik, P. Scheier, and T. D. Märk, Chem. Phys. Lett. 377, 74 (2003).

${ }^{21}$ H. Abdoul-Carime, S. Gohlke, and E. Illenberger, Phys. Rev. Lett. 92, 168103 (2004).

${ }^{22}$ S. Denifl, S. Ptasinska, M. Probst, J. Hrusak, P. Scheier, and T. D. Märk, J. Phys. Chem. A 108, 6562 (2004).

${ }^{23}$ See, for example, T. Skalicky, C. Chollet, N. Pasquier, and M. Allan, Phys. Chem. Chem. Phys. 4, 3583 (2002).

${ }^{24}$ P. Colarusso, K. Zhang, B. Guo, and P. F. Bernath, Chem. Phys. Lett. 269, 39 (1997).

${ }^{25}$ R. Abouaf, J. Pommier, and H. Dunet, Chem. Phys. Lett. 381, 486 (2003).

${ }^{26}$ R. Abouaf and H. Dunet, Eur. Phys. J. D 35, 405 (2005).

${ }^{27}$ K. Aflatooni, A. M. Scheer, and P. D. Burrow, Chem. Phys. Lett. 408, 426 (2005).

${ }^{28}$ D. Klar, M.-W. Ruf, and H. Hotop, Int. J. Mass. Spectrom. 205, 93 (2001).

${ }^{29}$ H. Abdoul-Carime, S. Gohlke, E. Fischbach, J. Scheike, and E. Illenberger, Chem. Phys. Lett. 389, 267 (2004).

${ }^{30}$ R. Barrios, P. Skurski, and J. Simons, J. Phys. Chem. B 106, 7991 (2002).

${ }^{31}$ D. M. Pearl, P. D. Burrow, J. J. Nash, H. Morrison, D. Nachtigallova, and K. D. Jordan, J. Phys. Chem. 99, 12379 (1995). 